\title{
The Damage Index Characteristics Research of Ms6.5 in Hualian County, Taiwan in 2018
}

Zongchao Li, Xueliang Chen, Qing Wu, Tiefei Li, Changlong Li Institute of Geophysics, China Earthquake Administration Beijing 100081, China lizongchaoigo@163.com

\section{8 年台湾地区花莲县 Ms6. 5 级地震损 伤指数特征研究}

\author{
李宗超, 陈学良, 吴清, 李铁飞, 李昌珑 \\ 中国地震局地球物理研究所 \\ 北京 100081，中国 \\ lizongchaoigo@163.com
}

Abstract: On February 4, 2018, a Ms6.5 occurred in Hualien County in Taiwan Province. The source depth was $10 \mathrm{~km}$. This earthquake killed 17 people and injured 285 people. The earthquake also caused huge property losses. Most of the casualties of the earthquake were caused by the collapse and damage of the buildings. The near field strong ground motion was the direct reason which caused the collapse of the building. The collapse of the buildings was greatly related to the amplitude and frequency of circulation of ground motion. The seismic response of system accumulated damage under cyclic load depends not only on the maximum amplitude of motion but also on the duration of motion. Many researchers suggest that the effective number of ground motion cycles is more reflective of seismic damage than the duration. The destructive ability of seismic ground motion depends on the amplitude of the movement and the number of cycles. In the geotechnical earthquake engineering, the number of motion cycles is the most important. Many researchers believe that the number of motion cycles is also an important factor in structural seismic design and damage assessment. Because the strength, stiffness and energy dissipation of the structure decreases with the increase of the load cycle, the amplitude itself is not sufficient to evaluate the seismic performance of the structure. In this paper, the spatial distribution characteristics of the damage index of Hualian earthquake is analyzed, and the correlation between the damage index and seismic intensity is analyzed.

Keywords - damage Index, Hualian eartrhquake, characteristics analysis, seismic intensity

摘要: 2018 年 2 月 4 日, 台湾省花莲县附近海域(北 纬 24.2 度, 东经 121.72 度) 发生 6.5 级地震, 震 源深度 10 千米, 地震造成 17 人遇难, 285 人受伤,
地震也造成了巨大的财产损失。本次地震的绝大部 分伤亡是由于建筑物倒塌破损造成的, 而近场强地 震动是造成建筑物倒塌的直接原因, 建筑物倒塌与 地震动的振幅和循环次数相关性极大。系统在循环 荷载下累积损伤的地震响应不仅取决于运动的最 大振幅, 还取决于运动的持续时间。许多研究人员 提出, 有效的地面运动周期数比持续时间更能反映 地震破坏能力。地震地面运动的破坏能力取决于运 动的振幅和循环次数。在岩土地震工程中, 运动循 环次数是最重要的。许多研究人员认为, 运动循环 次数也是结构抗震设计和损伤评估方面的一个重 要因素。由于结构的强度、刚度和耗能能力随着荷 载循环次数的增加而降低, 因此振幅本身不足以评 估结构的抗震性能。本文将着重分析研究了花莲地 震的损伤指数的空间分布特征, 并结合实际的灾害 烈度分布特征, 分析了震害指数与地震烈度的相关 性。

关键词: 损伤指数, 花莲地震, 特征分析, 地震强 度

\section{I. 引言}

2018 年 02 月 06 日, 台湾地区花莲县近 海区域发生 Ms6.5 级地震, 震中位置 (121.680E，24.158N)，位于花莲县政府北偏 东 $18.3 \mathrm{~km}$ （图 1)，震源深度 $9.5 \mathrm{~km}$ 。据台湾 中央气象厅信息, 此次地震最大烈度为VIII度, 其他附近县市烈度为 II - III度 (图 2), 最大烈度 出现在花莲县花莲市和宜兰县南澳市, 为VII度 (台湾国家实验研究院)。本次地震在台湾地 区不算是地震动强度较大的地震, 但本次地震 造成花莲市统帅大饭店、云翠大楼等多座楼房 倒塌, 有 17 人遇难, 285 人受伤。

台湾东部是地震多发区, 花莲县历史上曾 
发生多次破坏性地震, 1951 年 10 月 22 日, 花莲近海连续发生 7.3 级和 7.1 级两次强烈地 震。花莲县位于台湾东北方向, 而台湾位于欧 亚板块和菲律宾海板块的聚合交界地带 (李宗 超, 2018)。花东纵谷 (花莲) 是这 2 个板块 的交界线。由于这 2 个板块互相推挤、挤压, 会产生地震。此次花莲县也同样发生了两次较 强地震, 表明该地区有不同一般的地震孕育机 制, 一旦发生大的地震, 可能会伴随多个破坏
性地震同时出现。

地震损伤指数是与加速度有很大相关性 的可以表征地震造成的灾害程度的地震动参 数。损伤指数的计算方法是将加速度记录中各 周期的振幅相加, 得出 $\mathrm{c}$ 指数, 然后确定不同 振幅周期的相对权重, 并乘以 Malhotra (2002) 提出的 C 线性比例因子, 并通过雨流计数算法 识别加速度记录的周期和相应的周期振幅 (ASTM，1985）。

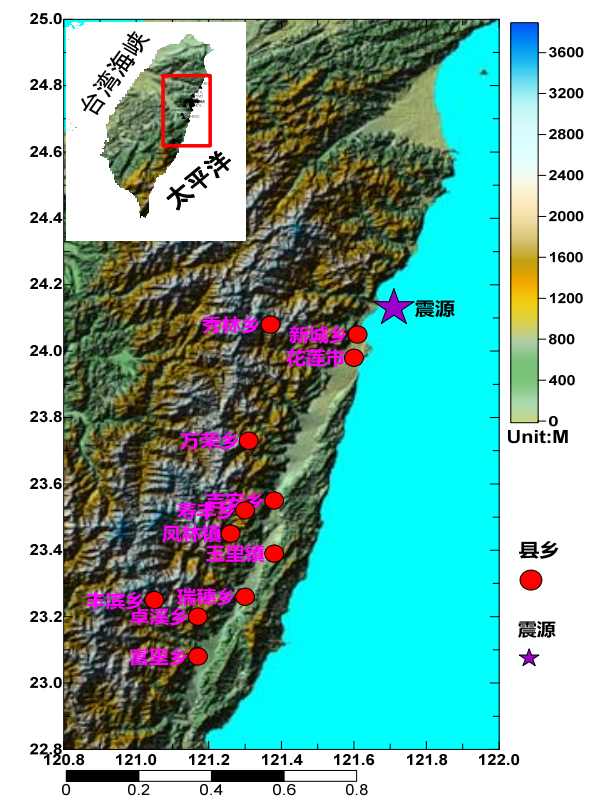

图 1 花莲地震镇中位置及台站分布. 红色实心圆点为震区周边行政县乡, 紫色五角星为震源位置.

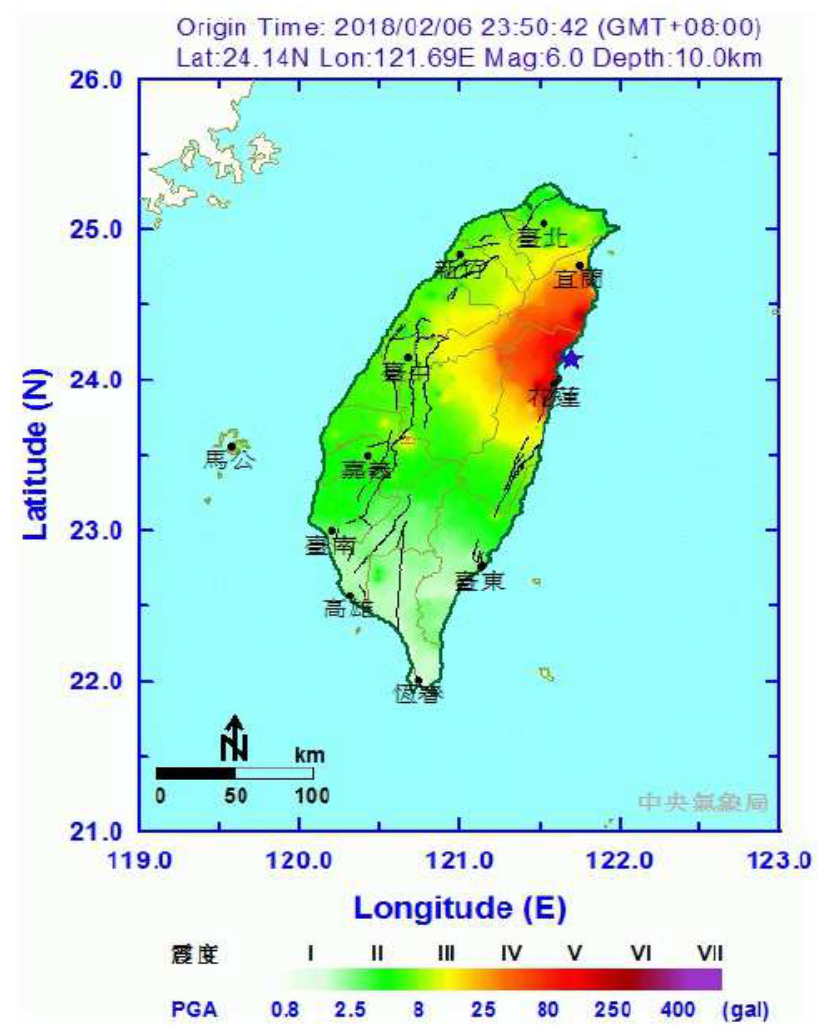

图 2 花莲 6.5 级地震 PGA 空间分布等震线图及地震烈度分布图（台湾省中央气象厅绘制） 


\section{II. 地震损伤指数空间分布特征分析}

本文以花莲地震加速度记录为基础, 分析 此次地震的地震损伤指数的分布特征。我们选 取了花莲地震震源周边 20 个台站的强震记录 进行分析研究 (表 1)。地震损伤指数是与加 速度有很大相关性的可以表征地震造成的灾 害程度的地震动参数。损伤指数的计算方法是 将加速度记录中各周期的振幅相加, 得出 $\mathrm{c}$ 指 数, 然后确定不同振幅周期的相对权重, 并乘 以 Malhotra (2002) 提出的 C 线性比例因子, 并通过雨流计数算法识别加速度记录的周期 和相应的周期振幅（ASTM，1985）。
地震损伤指数在花莲市区西部是最大的, 向北灾害指数越来越大, 花莲市往南灾害指数 越来越小。结合图 1 所示的花莲市地形特征, 花莲市以南的局部区域为平原地带, 花莲市西 北的局部区域为山区地形, 从花莲市区往西北 方向的局部区域内, 地震损伤指数有增大的趋 势, 地形特征对地震损伤指数有较大的影响。 同时, 在花莲市区及周边, $\mathrm{E}-\mathrm{W}$ 方向分量上的 地震损伤指数比 $\mathrm{N}-\mathrm{S}$ 方向分量的地震损伤指 数偏大, 表现出水平方向的分量差异。

表 1 花莲地震强震台站基本信息

\begin{tabular}{lllll}
\hline 编号 & 经度 & 纬度 & 震中距 km & 方位角 \\
\hline HWA007 & 121.6262 & 23.9865 & 19.76 & 196.0778 \\
HWA008 & 121.603 & 23.9873 & 20.46 & 202.514 \\
HWA009 & 121.6223 & 23.9903 & 19.48 & 197.5415 \\
HWA010 & 121.6027 & 23.9783 & 21.4 & 201.5708 \\
HWA011 & 121.5948 & 23.9953 & 19.99 & 205.6954 \\
HWA012 & 121.6313 & 23.992 & 18.91 & 195.0823 \\
HWA013 & 121.5985 & 23.9755 & 21.85 & 202.3103 \\
HWA014 & 121.6057 & 23.9712 & 22.02 & 200.0763 \\
HWA019-2-HWA 121.6135 & 23.975 & 21.37 & 198.4643 \\
HWA020-ESL & 121.4417 & 23.812 & 45.35 & 212.372 \\
HWA023-TWD & 121.6045 & 24.0812 & 11.45 & 222.0724 \\
HWA048 & 121.5805 & 24.0095 & 19.31 & 211.6151 \\
HWA050 & 121.5908 & 23.9878 & 20.92 & 205.7148 \\
HWA058-ETM & 121.4928 & 23.9658 & 28.56 & 221.8458 \\
HWA060-EYL & 121.6017 & 23.9035 & 29.29 & 195.7945 \\
HWA062-HWAP & 121.6198 & 23.9797 & 20.67 & 197.2356 \\
HWA063 & 121.593 & 23.9935 & 20.25 & 205.9161 \\
HWA067 & 121.4688 & 23.7545 & 49.59 & 205.7305 \\
ILA050-2-ENA 121.5908 & 23.9878 & 20.92 & 205.7148 \\
TRB042 & 121.6038 & 24.0003 & 19.11 & 203.9351 \\
\hline
\end{tabular}

III. 地震损伤指数与花莲地震灾害的相关性 我们分析地震动的水平方向的东西和南 北方向的差异是导致此次花莲市区较多建筑 损坏的原因之一 (图 3)。本次地震倒塌的建 筑物有一个共同的特点, 即低楼层柱子多、墙
体少, 建筑物又位于米仑断层带附近, 再加上 水平向地震动在两个方向分量上的差异。一遇 到强震, 脆弱的一楼支撑不住上方楼层的重 量, 出现倾斜倒塌。 
(3a)

(3b)
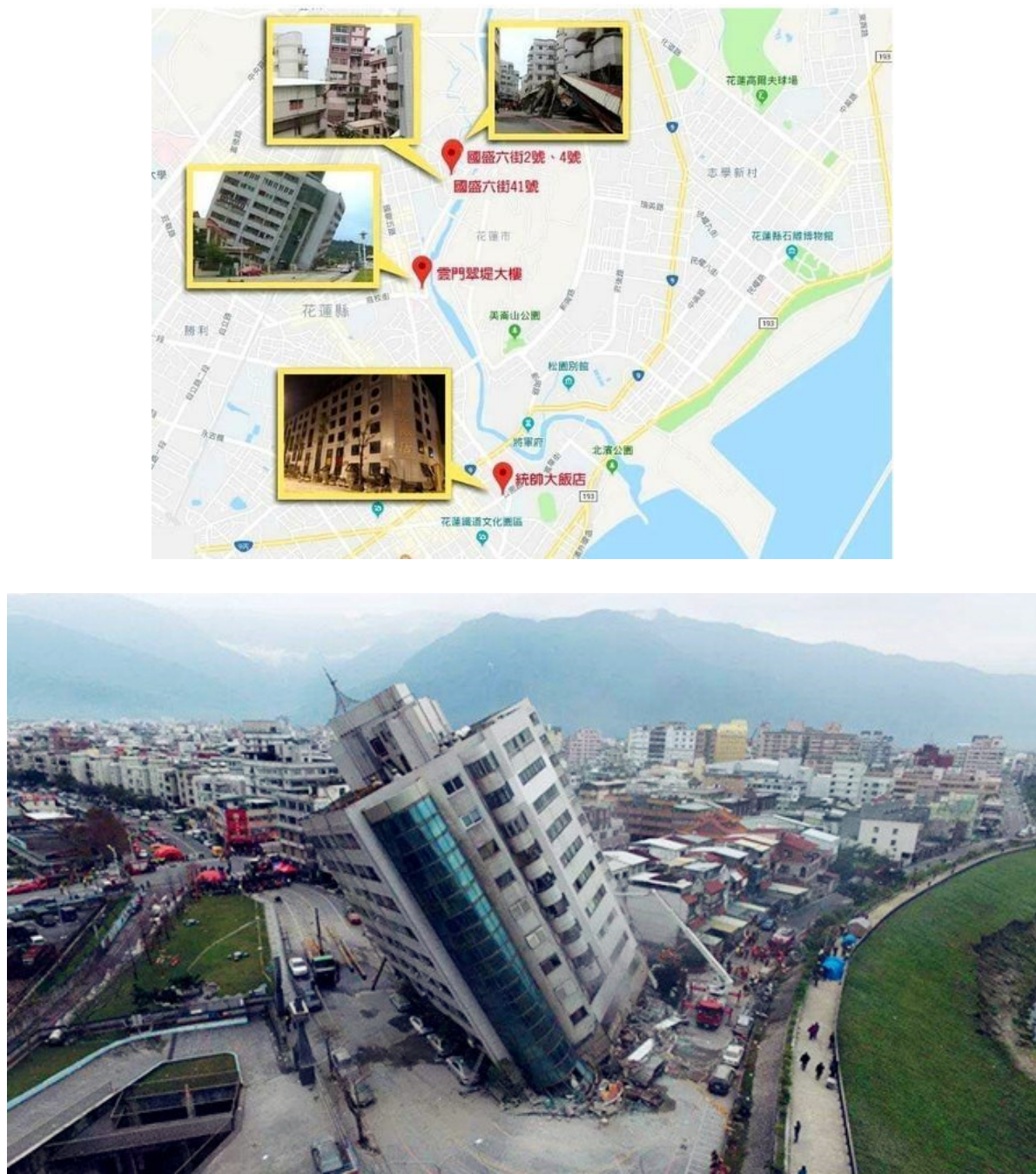

图 3 花莲地震主要建筑物倒塌破坏位置(台湾国家实验研究院). (3a) 花莲地震主要破坏性建筑 物的位置; (3b) 云翠大楼破坏倒塌情况。

地震作用下, 导致建筑物倒塌的因素很估模型及应用研究（2018YFC1504601），以 多, 比如建筑物抗震设防过低, 建筑物年久失 修, 建筑物自身振动周期与地震动卓越周期一 致导致建筑物共振等众多的原因, 在本文的研 究中, 我们发现地震损伤指数的空间分布特征 以及该参数在水平方向上 E-W 方向分量和 $\mathrm{N}-\mathrm{S}$ 方向分量上的差异与建筑物倒塌的较为 相似, 我们认为地震损伤指数在一定程度上是 可以表征花莲地震建筑物损害主要的特征的。 更加深入的研究地震损伤指数与建筑物倒塌 损坏的相关性对于提高建筑物抗震能力也将 具有重要的科学参考价值。

致谢

本研究所用数据来自中国台湾地区中央气象 局官(https://www.cwb.gov.tw/V7/earthquake/), 本研究受国家重点研发计划 “地震保险损失评
及中国地震局地球物理研究所基本科研业务 费专项（DQJB19B06， DQJB19A0131， DQJB19A0133）资助，在此表示感谢。

\section{参考文献}

[1]李宗超,陈学良, 吴健, 吴清.台湾地区花莲地震(M_s6.5) 工程地震动参数特征分析 [J]. 建筑结 构,2018,48(S2):308-313.

[2]台湾 “国家实验室研究院”（NARlabs）花莲地震概 要.2018.2.6, Ver 5.0.

[3] Malhotra PK. "Cyclic-demand spectrum" Earthquake Engineering and Structural Dynamics; Vol. 2002, 31, pp. 1441-1457.

[4] ASTM. Cycle counting in fatigue analysis, Annual Book of ASTM Standards, 1985, Vol. 03.01, Designation E1049-85 